find that it is a useful introductory text in this field. The greater part of the illustrative material used in the book is taken from research work on crop plants and, unlike most other modern books on the subject, the author's approach is non-mathematical.

The treatment is a description of the biological basis and practical utilization of quantitative variation rather than a statistical interpretation of the genetical basis of quantitative inheritance. Indeed, anyone interested in the latter approach would find the volume particularly disappointing. For example, the absence of a serious discussion of Mather's contributions to biometrical genetics and of his theory of polygenic inheritance is to be regretted in a book of this kind. Furthermore, the lack of treatment in depth of the basic tools and concepts of quantitative genetics, such as variance analysis, heritability, the variance analysis of diallel crosses and the coefficient of inbreeding, is an unfortunate omission in a specialist text-book on quantitative genetics. Advanced students of genetics will therefore find the treatment incomplete, but for non-specialists in biology and agriculture, the numerous examples and detailed description of methods supply a thorough basic understanding of the characteristics of quantitatively inherited variation.

The first three chapters are devoted to a historical introduction, to elementary statistics and to the basis and general nature of quantitative variation. Chapter 4 is a valuable assembly of detailed summaries of the behaviour of some of the best-known examples of quantitatively inherited characters in plants. The eight chapters which follow present the genetic basis of quantitative variation including: gene conversion, cytoplasmic and environmental effects, gene interaction, heterozygosis, allelic frequencies, gene mutation, correlated characters, the effect of competition on quantitative characters in populations of inbreeding and outbreeding species, the effects of inbreeding and the genetic basis of inbreeding depression. Regrettably, however, neither additive gene action nor directional dominance is discussed in connexion with the latter. Three chapters are devoted to selection where the emphasis is on description of methods of selection, particularly those used in plant breeding. There is also some discussion here of the principles underlying selection of quantitative characters such as heritability, the response to selection and correlated response (nebeneffekte der Selektion), but, in general, the treatment is rather brief and sketchy.

Heterosis is discussed at length in three chapters, one of which describes the methods used for the isolation and testing of inbred lines for superior combining ability in hybrids. Chapter 19 is a miscellany of breeding methods additional to those covered in previous chapters, including gamete selection, polycross testing, synthetic varieties and the utilization of male sterility. Finally, a very short chapter is devoted to "The System of Variability", and a concluding chapter recapitulates some of the main themes. There is a useful bibliography appended to each chapter, and the text is well supported by numerous tables and figures, and by author and subject indexes.

\section{WATRIN WILIIAMS}

\section{DEVELOPMENT OF A BIOLOGICAL THEORY}

\section{Heat and Life}

The Development of the Theory of Animal Heat. By Everett Mendelsohn. Pp. $x+208$. (Cambridge, Mass.: Harvard University Press; London: Oxford University Press, 1964.) 36s.

$\Lambda T$ the present time, when the volume of scientific literature is increasing at an overwhelming rate, less and less attention is paid to material and ideas published before the turn of the century. It is therefore very refreshing to trace the history of an important biological problem to that point in time when most modern developments take root. The choice of animal heat as a subject has been made carefully in order to provide a biological problem which has occupied the minds of philosophers and scientists since the earliest times and also one where the development of theory has been linked with advances in physics and chemistry. The problem of the origin of body heat is ideal for this purpose and, using it, the author sets out to investigate how far the reduction of a biological phenomenon to a physical analogue has been useful in biology.

The history begins with the Ancient Greeks who believed in a vital heat which burned in the heart. Even at this early stage, long before the experimental approach was used, a connexion between body heat and true fire was postulated, the breath serving both to cool the fire and fan the flame while food provided the fuel. No attempt was made, however, to put forward a physical or mechanical explanation for the warmth of the body, innate heat being regarded as mysterious and in some way akin to the heat of the Sun.

These, and similar views, were held until the seventeenth century and the beginnings of modern science. At this time Harvey, while still keeping the idea of an innate heat, suggested that the blood served to transport this heat about the body. In his later works the concept of innate heat lost for Harvey a little of its mystery and he tended to regard it simply as a property of blood. Descartes also held ideas about animal heat and he advanced a theory of the heart's motion based on the expansion of the blood as it entered the heart which was, he believed, extremely hot. In these notions Mr. Mendelsohn sees the first willingness on the part of mon to explain the action of the body in mechanical terms, and he traces the development of theory through Willis, van Helmont, Hook and Boyle. As he points out, the changes in biological theory at this time were related not so much to new information as to a new approach to the problem.

The next phase of development, in the later seventeenth century, consisted in further attempts to relate combustion and animal heat, and in the beginnings of the experimental approach. During this period Borelli was at least able to show that there was no burning heat in the heart. The emphasis then shifted in the early eighteenth century towards a mechanical explanation based on the heat of friction generated as the blood passed through the blood vessels. In spite of several attempts at measurement and calculation this period produced a great confusion of thought which, in Mr. Mendelsohn's opinion, stemmed partly from the lack of instruments and techniques but mainly from the primitive state of chemical and physical theory. The principal difficulty lay in the confusion of temperature with quantity of heat.

The step which was needed to form the basis of modern theory was made by such men as Black, Crawford and Lavoisier, who finally established the connexion between combustion and metabolism and recognized the importance of blood in the transport of oxygen and carbon dioxide. In the latter part of the book the author directs attention to the circumstances which made Lavoisier's ideas acceptable while similar theories had failed in the past. He concludes that progress in the theory of animal heat depended simply on progress in physics and chemistry, and suggests that further development was made because scientists were able to deal with the body in parts, regarding the blood, for example, simply as a liquid. The advances made since the time of Lavoisier are not mentioned, being the subject of a further investigation by $\mathrm{Mr}$. Mendelsohn.

Throughout the book there are numerous footnotes and references to writers of every period, and it is evident that the text is based on an extensive reading of the literature. The book would be useful reading for any student of biology.
D. L. INGRAM 